\title{
Plant extracts rich in polyphenols and vitamin $E$ protect cows fed an $n-3$ PUFA-rich diet against lipoperoxidation
}

\author{
M. Gobert, B. Martin, A. Ferlay, Y. Chilliard, B. Graulet, P. Pradel, D. Bauchart and D. Durand \\ Institut National de la Recherche Agronomique, Clermont-Ferrand/Theix, France
}

Lipid supplementation of ruminant diets with oilseeds rich in $n-3$ PUFA is a putative means of improving the nutritional quality of dairy products for consumers ${ }^{(1)}$. However, this regimen would increase the risk of lipoperoxidation in the plasma ${ }^{(2)}$ as well in tissues ${ }^{(3)}$. Studies in rats ${ }^{(4)}$ and sheep ${ }^{(5)}$ clearly show the bioefficiency and synergic effects of a mixture of plant extracts rich in polyphenols (PERP) and vitamin $\mathrm{E}$ (vit E) in the prevention of lipoperoxidation in the plasma. The PERP were obtained from rosemary (Rosemarinus officinalis), grape (Vinis vitifera), grapefruit (Citrus paradisi) and marigold (Calendula officinalis). The present experiment analysed the bioefficiency of vit $\mathrm{E}+\mathrm{PERP}$ in relation to plasma lipoperoxidation in lactating cows fed an $n-3$ PUFA-rich diet.

Twenty-four dairy cows were divided into four groups and the animals were fed for 5 weeks a maize-silage-based diet (control group); $n$ 6) or the same diet supplemented with extruded linseed (50 g oil $/ \mathrm{kg}$ diet DM; group L; $n$ 6), linseed + vit E ( $0.4 \mathrm{~g} / \mathrm{kg} \mathrm{diet} \mathrm{DM;} \mathrm{group} \mathrm{LE;}$ $n$ 6) or linseed + vit E+PERP ( $10 \mathrm{~g} / \mathrm{kg}$ diet DM; group LEP; $n$ 6). Plasma susceptibility to lipoperoxidation was evaluated using the peroxidizability index (PI; calculated from the fatty acid composition of plasma lipids) and variables of the in vitro kinetics of conjugated diene (CD) production (lag phase, maximal amount of $\mathrm{CD}$ and oxidation rate). Total antioxidant status and the activity of affected hepatic enzymes were also determined in the plasma of the cows.

Linseed-rich diets fed for 5 weeks increased plasma $n$-3 PUFA (3.6-fold) to the detriment of $n$ - 6 PUFA ( $-31 \%$ ), leading to a lower $n-6: n-3$ ( 1.5 v. 7.7 for the control group). Moreover, linseed-rich diets increased plasma PI by $13 \%$ after the 5 weeks of the experimental diets. Only the mix of vit E + PERP decreased the lipoperoxidation associated with linseed diets, as shown by a higher lag phase $(+47 \%$; $P<0.01)$ and a lower oxidation rate $(-48 \% ; P<0.01)$ compared with group L.

The addition of vit E+PERP to the linseed-rich diet helped to protect plasma lipids against peroxidation in the dairy cows. This protective action is probably associated with the lipophilic (vit E) and hydrophilic (PERP) properties of these dietary antioxidants, which are active in different phases of the peroxidation chain reaction. These PERP, tested on rat ${ }^{(4)}$ and sheep ${ }^{(5)}$, could thus play a putative role in protecting the health of high-producing dairy cows. This mix of antioxidants could permit an enrichment of dairy products with $n-3$ PUFA while preserving the bovine's health.

1. Chilliard Y, Glasser F, Ferlay A, Bernard L, Rouel J \& Doreau M (2007) Eur J Lipid Sci Technol 109, 828-855.

2. Scislowski V, Bauchart D, Gruffat D, Laplaud PM \& Durand D (2005) J Anim Sci 83, $2162-2174$.

3. Durand D, Scislowski V, Chilliard Y, Gruffat D \& Bauchart D (2005) Indicators of Milk and Beef Quality. EAAP Publication no. 112, pp. 137-150

[JF Hocquette and S Gigli, editors]. Wageningen, The Netherlands: Wageningen Academic Publishers.

4. Gladine C, Morand C, Rock E, Bauchart D \& Durand D (2007) Anim Feed Sci Technol 136, $281-296$.

5. Gladine C, Rock E, Morand C, Bauchart D \& Durand D (2007) Br J Nutr 98, 691-701. 